\section{Practicing Lateral Cervical Puncture for Myelography}

The result of the recent survey regarding cervical myelography by using a C1-2 puncture published by Yousem and Gujar ${ }^{1}$ is an important contribution to the neuroradiologic practice. The authors' excellent work demonstrates the rationale in an effort to maintain the existing skills, even requiring certain skills.

For a long time, we have practiced the lateral cervical approach with intrathecal puncture at level $\mathrm{C} 0$ - $\mathrm{Cl}$, between the occiput and the $\mathrm{C} 1 \mathrm{arch}^{2}$ In fact, this technique represents a lateral puncture of the cisterna magna (posterior cerebellomedullary cistern). It is well known that the subarachnoid space between the arch of $\mathrm{Cl}$ and the occiput shows substantial extension, with the posterior border corresponding to the connecting line between the posterior edge of the foramen magnum to the arch of $\mathrm{Cl}$. Consequently, above the level of the $\mathrm{C} 1 \mathrm{arch}$ is an abrupt increase of the distance between the posterior surface of the spinal cord to the posterior border of the subarachnoid space (assembling the extracranial part of the cisterna magna). Thus, the resulting volume of subarachnoid space at this level exceeds the subarachnoid space at the C1-C2 level substantially. Navigating the needle in the posterior part of the subarachnoid space at the $\mathrm{C} 0-\mathrm{Cl}$ level does basically prevent any unfavorable option of touching the spinal cord.

The advantage of the lateral approach at level $\mathrm{C} 0-\mathrm{C} 1$ includes 2 important features: 1) There are definitely less adverse effects than the C1-C2 approach because it avoids potential direct needle contact to the spinal cord surface. After ensuring the strong sagittal position of the head, to allow precise navigation, the needle can practically not get to the cord because its trajectory lies posterior to the cord surface. 2) This approach gives skilled individuals the option to apply this intrathecal puncture in rooms without fluoroscopy (eg, intensive care for diagnostic purposes, or direct in the CT room). In such cases, the needle should be inserted in a point 2 to $2.5 \mathrm{~cm}$ posterior to the mastoid apex in a virtual line parallel to the orbitomeatal line. The needle will be advanced with slowly successive movement, sliding the posterior surface of the occiput to the point of penetration of the dura mater in the lateral and posterior parts of the suboccipital cisterna magna.

\section{References}

1. Yousem DM, Gujar SK. Are C1-2 punctures for routine cervical myelography below the standard of care? AJNR Am J Neuroradiol 2009 April 15 (Epub ahead of print)

2. Mironov A. Laterale suboccipitale punktion der cisterna magna cerebellomedullaris [Lateral suboccipital puncture of the cisterna magna (author's transl)]. Neurochirurgia (Stuttgart) 1981;24:150-51

A. Mironov

Department of Radiology Creighton University Medical Center

Omaha, Neb 